\title{
The effect of cognitive-behavioural therapy on the reproductive health of women with HIV: a randomised controlled trial
}

\author{
Atefeh Nobakht ${ }^{1}$, Minoo Mohraz ${ }^{2}$, Mitra Rahimzadeh ${ }^{3}$, Maryam Tehranizadeh ${ }^{4}$, Zahra Bayat-Jozani², \\ Sara Esmaelzadeh ${ }^{5}$ \\ ${ }^{1}$ MS Student in Midwifery, Alborz University of Medical Sciences, Karaj, Iran \\ ${ }^{2}$ Iranian Research Center of HIV/AIDS, Iranian Institute for Reduction of High-Risk Behaviors, Tehran University of Medical \\ Sciences, Tehran, Iran \\ ${ }^{3}$ Social Determinants of Health Research Center, Alborz University of Medical Sciences, Karaj, Iran \\ ${ }^{4}$ Payam Noor University, Karaj, Iran \\ ${ }^{5}$ Social Determinants of Health Research Center, Faculty of Nursing and midwifery, Alborz University of Medical Sciences, Karaj, \\ Iran
}

\begin{abstract}
Introduction: Acquired immune deficiency syndrome (AIDS) is generally related to reproductive health and is most commonly transmitted through injection addiction, sexual relationship, pregnancy, and breastfeeding. Therefore, the promotion of reproductive health of women with human immunodeficiency virus (HIV) is very important. The aim of this study was to investigate the effect of counselling on cognitive-behavioural therapy (CBT) on reproductive health in women with HIV.

Material and methods: This randomised controlled trial was conducted in 2017. Sixty HIV-infected women who referred to Imam Khomeini Hospital Consultation Centre for clients with risky behaviour in Tehran participated in this study. The sampling method was census, and samples were randomly assigned to two groups: control and intervention. In addition to routine care, the intervention group received seven cognitive-behavioural counselling sessions on reproductive health. The questionnaire used in this study was a reproductive health assessment scale for HIV-positive women.

Results: There was no statistically significant difference between the demographic characteristics in the control and intervention groups. The result of repeated measures test showed that the length of time affects the total score of reproductive health $(p<0.000)$ and there was a significant difference between the two groups $(p<0.000)$.

Conclusions: It is suggested that CBT counselling approaches be included in educational programs for the health of women with HIV. Given the widespread dimensions of reproductive health, counselling with a cognitive therapy approach in each dimension with the number of further sessions is suggested.
\end{abstract}

HIV AIDS Rev 2017; 16, 4: 236-243

DOI: https://doi.org/10.5114/hivar.2017.71911

Key words: cognitive-behavioural therapy, HIV, reproductive health.

Address for correspondence: Dr. Sara Esmaelzadeh, School of Nursing and Midwifery, Alborz University of Medical Sciences, 009814576982 Tehran, Iran, phone: 00989126232569 ,

e-mail: esmaelzadeh1360@gmail.com
Article history:

Received: 05.11.2017

Received in revised form: 13.11.2017

Accepted: 18.11.2017

Available online: 30.11 .2017
International Journal of HIV-Related Problems

HIV \& AIDS

R e vi e w 


\section{Introduction}

About 1.9 million adults are infected with human immunodeficiency virus (HIV) every year, and $10.5 \%$ are aged between 15 and 49 years, of which 1.4 million are women. Approximately 220,000 cases of infection occur during pregnancy and breastfeeding [1]. According to registered persons, acquired immune deficiency syndrome (AIDS) in Iran has been reported in 34,949 people as of April 1, 2017, and more than $50 \%$ of cases occur at an age when the person is sexually active [2]. With the increase in HIV-positive women and the increased life expectancy associated with the use of antiretroviral drugs, there is a need for more knowledge about the reproductive health of infected women [3]. HIV/AIDS is generally related to reproductive health and is the most commonly transmitted through sexual relationship, pregnancy, and childbirth [4]. Therefore, promoting the reproductive health of HIV-positive women is very important [5]. Women's reproductive decisions are influenced by their culture, especially women living in societies in which the value of women is related to childbearing [3]. Women with HIV also have to be aware of their sexual and reproductive rights, they must have access to medical consultants and services to facilitate informed decision making on reproductive health [6]. With prevention of mother-tochild transmission (PMTCT), the risk of transmission from mother to child is reduced from $15-45 \%$ to $2 \%$ [7]. New recommendations for safe abortion, HIV disclosure skills, empowerment and self-efficacy interventions, and identification of key research gaps are parts of the World Health Organization (WHO) guidelines process for HIV-positive women [8]. AIDS and reproductive health are the common root causes of such things as poverty, gender inequality, and the social marginalisation of vulnerable populations $[9,10]$. Sometimes, due to the disclosure of HIV status, patients are condemned by the family for immoral practices and breaking sexual norms [11]. Stigma and discrimination are key barriers to sexual and reproductive health and are also causes of fear, anxiety, and non-disclosure of HIV status [12].

The need for counselling on reproductive health services is a part of the treatment and care of standard HIV services for people with AIDS [13]. Cognitive-behavioural therapy (CBT) is one of the various approaches to deal with AIDS-related mental health emotions; it helps the patient to identify others, their environment, and the problems that disturbed them, and to create new thoughts in the person that makes it possible to have better manner [14]. Through CBT, it is possible to influence the health, quality of life [15], physical health, substance abuse [16], depression and adherence to treatment [17], immune system, disease progression [18], nausea in antiretroviral therapy (ART) drug use [19], stress disorders, and insomnia in people with HIV [20].

Providing a framework for planning through better protection, support, and realisation of the sexual and reproductive rights of women with HIV can be helpful [21]. In a study to assess the reproductive health needs of people with HIV, the results of the study showed the requirement for counselling and support on reproductive and sexual health [22]. In another study that looked at the fertility intentions of women with HIV, it was shown that these tendencies are affected by the health care system, previous pregnancy experiences, and support for health care providers and relatives [23]. Such interventions are designed to increase women's sexual and reproductive decision making and related health outcomes. However, although some interventions have been evaluated, the effectiveness of CBT has not been assessed.

\section{Material and methods}

This study was a randomised controlled trial study. Participants in this study were all women with HIV, who referred to counselling centres for high-risk behaviours in Imam Khomeini Hospital in Tehran. This centre is the referral counselling centre, and people come to the centre from different parts of the province and even the country. Three hundred women with HIV have registered in this centre. After consulting with health providers in this centre, it was revealed that there were 66 participants in the centre, who had inclusion criteria for participation in the study, and some people only receive medication and refer to this centre to hide their disease in their cities and do not have enough time to participate in counselling session. Hence, the sample size in this study was 66 women by census method. Inclusion criteria for study were: being Iranian, being in the reproductive age of 15-45 years old, having the ability to read and write, and being sexually active. And the criteria of exclusion were: severe addiction such that they had no ability to respond to the questions, having a history of psychiatric disorders confirmed by a doctor, having advanced stages of the disease, and not attending more than three sessions of training classes. One woman who did not want to participant in study and five women who did not participant in more than three sessions of counselling were excluded from the study (Fig. 1). Thirty women participated in the control group and 30 women participated in the intervention group. Sampling lasted from April to August 2017. The researcher was a student in MS counselling midwifery and in the skills of CBT, and had received the necessary training. After obtaining necessary permission from the faculty and the university, each participant was called by phone and after explaining the objectives and obtaining oral consent, the samples, according to recorded file, were randomly assigned to two groups by table numbers. After determining the groups, and before the study started, written consent was obtained from each woman, and before the beginning of the intervention, the total scores of reproductive health and factors in the two groups were determined by questionnaire.

The questionnaire in this study had two parts: the first part included the demographic characteristics, and the second part comprised the reproductive health questionnaire of women with HIV. This questionnaire had 36 questions, including six factors (physical and parental concerns, social 


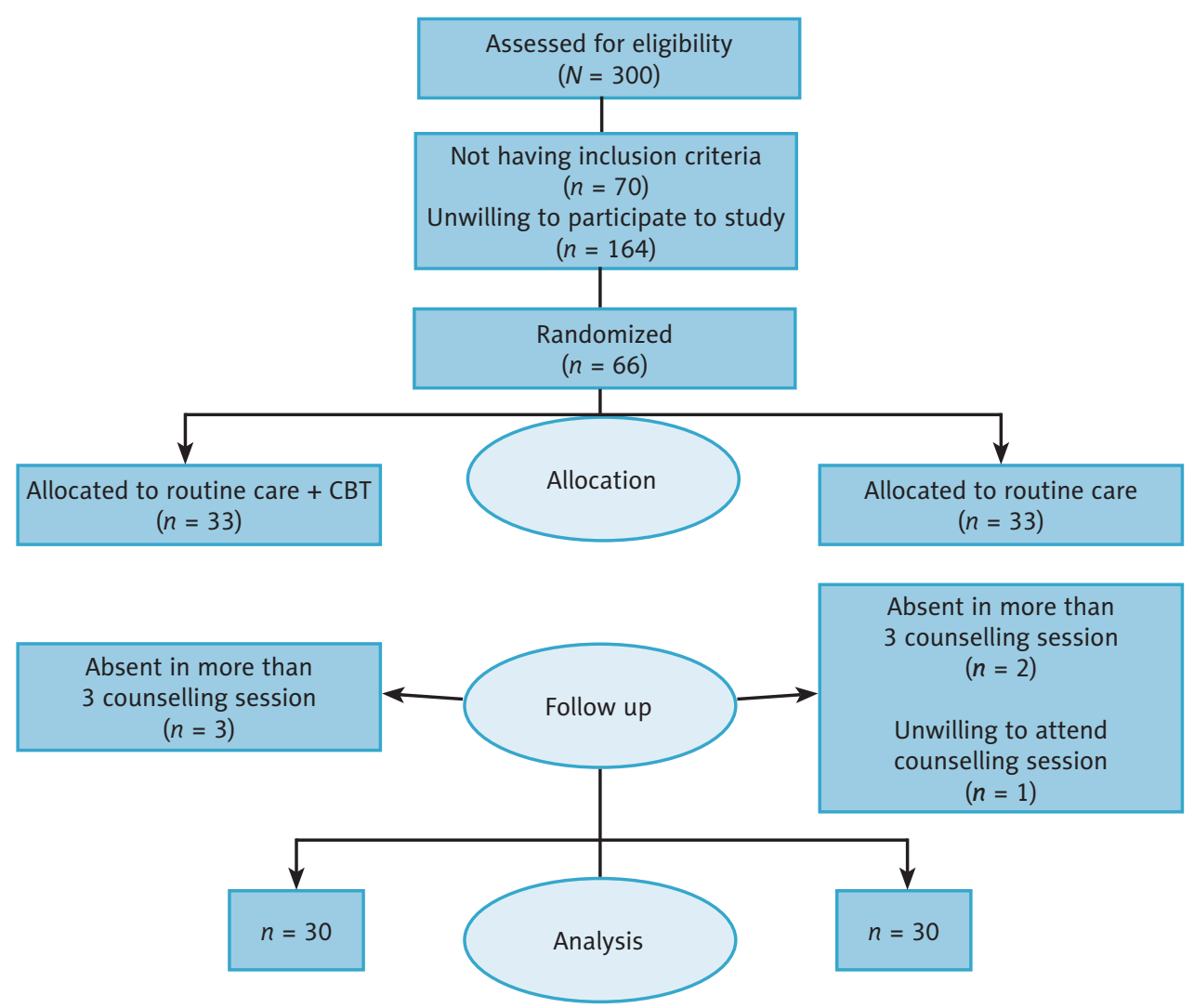

Figure 1. Consort flow diagram of study

problems and disclosure status, life instability and sexual issues, psychological concern, coping with HIV, and responsible sexual behaviour). Cronbach's a coefficient for the reliability of this questionnaire for all dimension was 0.713 , and its external reliability as evaluated by the test-retest method and intra-class correlation was 0.952 [5]. Before, after, and one month after the intervention, reproductive health scores were analysed.

The intervention group had seven sessions of counselling with a CBT approach on reproductive health, which lasted for 90 minutes twice a week. The content of the sessions was approved by the faculty members of the Department of Midwifery, Psychiatry, Psychology, and Infectious Diseases of Alborz University and included the following:

- session 1: discussion about the person's attitudes and behaviour in relation to reproductive health and feelings that they have experienced,

- session 2: awareness of the effects of the disease on the individual's body, the ways to cope with it, the changes and discomforts experienced by the patient, and with those problems,

- session 3: explaining about the psychological problems that people have encountered, the person's mindset about the disease, and the feelings that she has experienced with the disease; an explanation of the psychological empowerment strategies of the person,
- session 4: an explanation of the pregnancy and the way of preventing PMTCT, childbearing intentions and thinking about it, experiences with previous pregnancy, and pregnancy morbidity,

- session 5: increasing awareness about sexual relations, brief training of the sexual response circle, the impact of HIV on sexual relationships, strategies for improving sexual relations, attitudes about sex and the problems faced with this, experiences of sexual health, and dealing with sexual problems,

- session 6: expressing issues of self-disclosure to a partner, family members, and others, counselling on ways to prevent transmission to sexual partners and others,

- session 7: understanding the way people think about responsible behaviour, and the problems facing the person, the need to communicate with the family, the reasons for disconnection with the family, and an explanation about finding discrimination and stigma reduction.

In order to observe the ethics in the research, control group participants received a handbook with advice, given after the study.

\section{Results}

Table 1 shows the demographic characteristics of the subjects participating in the study. There was no significant dif- 
Table 1. Characteristic of HIV positive women

\begin{tabular}{|c|c|c|c|}
\hline \multirow{2}{*}{ Variable } & Intervention & Control & \multirow{2}{*}{$p$ value } \\
\hline & Frequency (\%) & Frequency (\%) & \\
\hline \multicolumn{4}{|l|}{ Age } \\
\hline $20-24$ & $0(0.0)$ & $2(6.7)$ & $0.8^{*}$ \\
\hline $25-29$ & $6(20.0)$ & $2(6.7)$ & \\
\hline $30-34$ & $4(13.3)$ & $4(13.3)$ & \\
\hline $35-39$ & $8(26.7)$ & $13(43.3)$ & \\
\hline $40-45$ & $12(40.0)$ & $9(30.0)$ & \\
\hline \multicolumn{4}{|l|}{ Education } \\
\hline Primary school & $7(23.3)$ & $5(16.7)$ & $0 / 5^{* *}$ \\
\hline Secondary & $8(26.7)$ & $4(13.3)$ & \\
\hline High school & $6(20.0)$ & $6(20.0)$ & \\
\hline Diploma & $7(23.3)$ & $11(36.7)$ & \\
\hline University & $2(6.7)$ & $4(13.3)$ & \\
\hline \multicolumn{4}{|l|}{ Job } \\
\hline House keeper & $19(63.3)$ & $20(66.7)$ & $0.5^{* * *}$ \\
\hline Jobless & $6(20.0)$ & $4(13.3)$ & \\
\hline Worker & $0(0.0)$ & $1(3.3)$ & \\
\hline Employer & $3(10.0)$ & $1(3.3)$ & \\
\hline Self-employment & $2(6.7)$ & $4(13.3)$ & \\
\hline \multicolumn{4}{|l|}{ Currently living child } \\
\hline No child & $11(36.7)$ & $9(30.0)$ & $0.0^{* * * *}$ \\
\hline 1 & $8(26.7)$ & $8(26.7)$ & \\
\hline 2 & $7(23.3)$ & $12(40.0)$ & \\
\hline 3 & $3(10.0)$ & $1(3.3)$ & \\
\hline 4 and more & $1(3.3)$ & $0(0.0)$ & \\
\hline \multicolumn{4}{|l|}{ Infected child } \\
\hline Dose not have a child & $27(90.0)$ & $26(86.7)$ & $0.6^{\star *}$ \\
\hline Have a child & $3(10.0)$ & $4(13.3)$ & \\
\hline \multicolumn{4}{|l|}{ Partners status } \\
\hline Positive & $18(60.0)$ & $16(53.3)$ & $0.8^{* \star *}$ \\
\hline Negative & $10(33.3)$ & $10(33.3)$ & \\
\hline \multicolumn{4}{|l|}{ Transmission } \\
\hline Spouse & $22(73.3)$ & $19(63.3)$ & $0.2^{\star * *}$ \\
\hline Addiction & $0(0.0)$ & $4(13.3)$ & \\
\hline Sex with others & $4(13.3)$ & $3(10.0)$ & \\
\hline Others & $4(13.3)$ & $4(13.3)$ & \\
\hline \multicolumn{4}{|l|}{ Marital status } \\
\hline Single & $11(36.7)$ & $9(30.0)$ & $0.9^{* * *}$ \\
\hline Married & $15(50.0)$ & $17(56.7)$ & \\
\hline Divorcee & $2(6.7)$ & $3(10.0)$ & \\
\hline Widow & $2(6.7)$ & $1(3.3)$ & \\
\hline \multicolumn{4}{|l|}{ Unwanted pregnancy } \\
\hline Positive & $11(36.7)$ & $13(43.3)$ & $0.4^{* * *}$ \\
\hline Negative & $19(63.3)$ & $17(56.7)$ & \\
\hline
\end{tabular}


Table 1. Cont.

\begin{tabular}{|c|c|c|c|}
\hline \multicolumn{4}{|l|}{ Duration of HIV } \\
\hline Under 1 year & $0(0.0)$ & $2(6.7)$ & $0 / 1^{* * *}$ \\
\hline $2-5$ years & $22(73.3)$ & $15(50.0)$ & \\
\hline $6-10$ & $4(13.3)$ & $10(30.0)$ & \\
\hline 10 years and more & $4(13.3)$ & $3(10.0)$ & \\
\hline \multicolumn{4}{|l|}{ Addiction } \\
\hline Yes & $3(10.0)$ & $4(13.3)$ & $0.1^{* * *}$ \\
\hline No & $27(90.0)$ & $26(86.7)$ & \\
\hline \multicolumn{4}{|l|}{ Treatment status } \\
\hline On antiretroviral treatment & $26(86 / 7)$ & $28(93.3)$ & 1.0 ** \\
\hline Not on antiretroviral treatment & $4(13.3)$ & $2(6.7)$ & \\
\hline \multicolumn{4}{|l|}{ Use of contraception } \\
\hline Positive & $22(73.3)$ & $22(73.3)$ & $1.0^{\star * *}$ \\
\hline Negative & $8(26.7)$ & $8(26.7)$ & \\
\hline \multicolumn{4}{|l|}{ Type of contraceptive } \\
\hline Tubectomy & $0(0.0)$ & $2(6.7)$ & 0.1 \\
\hline Injectable & $1(3.3)$ & $0(0.0)$ & 0.4 \\
\hline Male condom & $17(56.7)$ & $20(66.7)$ & 0.6 \\
\hline Withdraw & $2(6.7)$ & $2(6.7)$ & 1.0 \\
\hline Pill & $3(10.0)$ & $0(0.0)$ & 0.2 \\
\hline None of them & $8(26.7)$ & $8(26.7)$ & - \\
\hline \multicolumn{4}{|l|}{ Dual peventation } \\
\hline Yes & $1(3.3)$ & $2(6.7)$ & $0.7^{* * *}$ \\
\hline No & $29(96.7)$ & $28(93.3)$ & \\
\hline \multicolumn{4}{|l|}{ Number of sex partner } \\
\hline One person & $14(46.6)$ & $13(43.3)$ & $0.2^{* * *}$ \\
\hline More of one person & $16(53.4)$ & $17(56.7)$ & \\
\hline
\end{tabular}

ference between the demographic characteristics in the control and intervention groups.

The result of the repeated measures ANOVA showed that the score of parental and physical concerns did not change over time $(p<0.217)$, but there was a significant difference between the two groups $(p<0.000)$. The result of repeated measures test showed that time length affected the scores of social problems and the disclosure of the disease $(p<0.000)$, and there was a significant difference between the two groups $(p<0.000)$. The result of the repeated measures test revealed that time length influenced the psychological concern $(p<0.02)$, and there was a significant difference between the two groups $(p<0.000)$. The result of the repeated measures showed that the responsible behaviour score was not changeable during the time $(p<0.21)$, and there was no significant difference between the two groups $(p<0.13)$. The result of repeated measures test showed that the length of time influenced the score of psychological concern, and there was no significant difference between the two groups in terms of life instability and sexual issues ( $p<0.14$ vs. $p<0.001$ ). The result of the repeated measures test showed that the length of time influenced the score of coping with HIV $(p<0.000)$ and there was a significant difference between the two groups $(p<0.000)$. The result of repeated measures test showed that the length of time affected the total score of reproductive health $(p<0.000)$, and there was a significant difference between the two groups $(p<0.000)$ (Table 2).

\section{Discussion}

The results of the present study show the impact of counselling on the reproductive health of women with HIV, apart from the dimension of responsible behaviour.

In this study, one of the factors of reproductive health was parenting and physical concerns in HIV-infected women. Consultation with CBT had a positive effect on this dimension $(p<0.000)$. 
Table 2. Results of repeated measures in measuring three times of the reproductive health and factors score

\begin{tabular}{|c|c|c|c|c|c|c|}
\hline \multirow{2}{*}{ Variable } & \multirow{2}{*}{ Group } & \multirow{2}{*}{$\begin{array}{l}\text { Mean } \pm \text { SD } \\
\text { Before }\end{array}$} & \multirow{2}{*}{$\begin{array}{l}\text { Mean } \pm \text { SD } \\
\quad \text { After }\end{array}$} & \multirow{2}{*}{$\begin{array}{c}\text { Mean } \pm \text { SD } \\
\text { One month after }\end{array}$} & \multicolumn{2}{|c|}{ Repeated measure } \\
\hline & & & & & Within group & Between group \\
\hline \multirow{2}{*}{$\begin{array}{l}\text { Physical and } \\
\text { parental concerns }\end{array}$} & Intervention & $12.3 \pm 5.3$ & $15.2 \pm 4.8$ & $15.4 \pm 5.1$ & \multirow{2}{*}{$\begin{array}{c}\mathrm{F}=1.5 \\
p=0.217\end{array}$} & \multirow{2}{*}{$\begin{array}{c}\mathrm{F}=21.7 \\
p=0.000\end{array}$} \\
\hline & Control & $11.7 \pm 4.1$ & $10.3 \pm 3.7$ & $8.9 \pm 2.7$ & & \\
\hline \multirow{2}{*}{$\begin{array}{l}\text { Social problems } \\
\text { and HIV disclusure }\end{array}$} & Intervention & $12.2 \pm 4.9$ & $14.5 \pm 4.9$ & $19.4 \pm 5.4$ & \multirow{2}{*}{$\begin{array}{c}\mathrm{F}=45.3 \\
p=0.000\end{array}$} & \multirow{2}{*}{$\begin{array}{l}\mathrm{F}=16.0 \\
p=0.000\end{array}$} \\
\hline & Control & $12.1 \pm 4.2$ & $10.3 \pm 4.0$ & $13.5 \pm 3.5$ & & \\
\hline \multirow{2}{*}{$\begin{array}{l}\text { Psychological } \\
\text { concern }\end{array}$} & Intervention & $23.4 \pm 6.5$ & $27.7 \pm 7.4$ & $27.0 \pm 7.6$ & \multirow{2}{*}{$\begin{array}{c}\mathrm{F}=4.1 \\
p=0.02\end{array}$} & \multirow{2}{*}{$\begin{array}{c}\mathrm{F}=11.1 \\
p=0.000\end{array}$} \\
\hline & Control & $22.2 \pm 6.1$ & $21.7 \pm 5.9$ & $19.6 \pm 6.1$ & & \\
\hline \multirow{2}{*}{$\begin{array}{l}\text { Responsible } \\
\text { Behavior }\end{array}$} & Intervention & $25.8 \pm 11.3$ & $27.5 \pm 3.3$ & $27.6 \pm 5.1$ & \multirow{2}{*}{$\begin{array}{c}\mathrm{F}=1.5 \\
p=0.21\end{array}$} & \multirow{2}{*}{$\begin{array}{c}\mathrm{F}=2.1 \\
p=0.13\end{array}$} \\
\hline & Control & $23.1 \pm 5.4$ & $24.4 \pm 4.9$ & $20.9 \pm 4.2$ & & \\
\hline \multirow{2}{*}{$\begin{array}{l}\text { Instability of life } \\
\text { and sexual issues }\end{array}$} & Intervention & $8.9 \pm 2.6$ & $10.2 \pm 2.9$ & $10.7 \pm 3.0$ & \multirow{2}{*}{$\begin{array}{c}\mathrm{F}=1.9 \\
p=0.14\end{array}$} & \multirow{2}{*}{$\begin{array}{c}\mathrm{F}=1.7 \\
p=0.001\end{array}$} \\
\hline & Control & $9.4 \pm 2.4$ & $9.4 \pm 2.2$ & $8.5 \pm 2.2$ & & \\
\hline \multirow{2}{*}{$\begin{array}{l}\text { Coping with } \\
\text { disease }\end{array}$} & Intervention & $25.3 \pm 6.1$ & $33.0 \pm 4.7$ & $32.1 \pm 5.5$ & \multirow{2}{*}{$\begin{array}{c}\mathrm{F}=23.1 \\
p=0.000\end{array}$} & \multirow{2}{*}{$\begin{array}{l}\mathrm{F}=16.1 \\
p=0.000\end{array}$} \\
\hline & Control & $24.0 \pm 6.2$ & $24.3 \pm 7.6$ & $25.2 \pm 5.9$ & & \\
\hline \multirow{2}{*}{$\begin{array}{l}\text { Total score of } \\
\text { reproductive health }\end{array}$} & Intervention & $115.3 \pm 24.2$ & $122.0 \pm 20.5$ & $132.1 \pm 21.9$ & \multirow{2}{*}{$\begin{array}{c}\mathrm{F}=10.9 \\
p=0.000\end{array}$} & \multirow{2}{*}{$\begin{array}{l}\mathrm{F}=24.4 \\
p=0.000\end{array}$} \\
\hline & Control & $103.5 \pm 18.2$ & $100.5 \pm 17.3$ & $96.5 \pm 18.5$ & & \\
\hline
\end{tabular}

Today, HIV-positive women have controversies in receiving information on fertility. One such problem is that antiretroviral drugs reduce the risk of a vertical transmission of the virus from mother to foetus, and as a result, women hope for pregnancy and having a healthy child. In contrast, the stigma of HIV has a negative effect [24]. Additionally, the physical problems of infected people who are exposed to recurrent infections due to immunosuppression have an impact on their ability to work, and this affects the economic status of individuals and their reproductive tendencies and poses the possibility of high-risk sexual behaviours for their livelihood [23]. A study showed the positive effect of intervention with a cognitive-behavioural approach to stress management along with supportive therapies on people with HIV in health behaviours such as nutrition, physical activity, sexual relations, and tobacco use compared to pre-intervention [25]. One of the other factors of reproductive health was social problems, and the disclosure of disease in HIV-positive women while counselling on the cognitive-behavioural therapy approach had a positive effect on this dimension $(p=0.000)$. AIDS is a social and political issue [26]. Stigma, discrimination, lack of information, and lack of access to health services lead to non-testing of HIV/AIDS [27]. A study that was conducted through mobile phones to reduce the stigma, focusing on increased self-esteem and coping with AIDS, showed increased self-esteem in exposure to the stigma and coping with HIV [28]. Another study showed the positive effect of counselling in AIDS patients regarding disclosure of their HIV status and use of contraception [29].

Another factor of women's reproductive health was psychological concerns, which included the psychological state of individuals and their lives. Consultation with a cognitive-behavioural therapeutic approach had a positive effect on the mental health issues of HIV-positive women $(p<0.000)$. Women with HIV are more likely to be exposed to more problems than men due to more gender-related mental health problems. In a study conducted in 2015, the rate of depression and anxiety in HIV-positive women was reported to be higher than in men, and levels of depression among single, divorced, and widowed women were higher than in married women [30]. A study in Uganda showed that psychosocial counselling had no effect on the symptoms of depression in infected people but was associated with decreased anxiety in young people [31]. The results of a study in Zimbabwe showed the positive impact of psychosocial counselling on increasing self-acceptance in people with HIV [32]. The results of another study also showed that educational intervention increased problem-solving skills, decision-making power, and hope for the future in people with HIV, as well as improving mental health [33]. Other factors affecting the reproductive health dimensions of HIV-positive women were the instability of life and sexual issues, which included the quality and satisfaction of sexual relations and marital satisfaction. Consultation with cognitive-behavioural therapy had a positive effect on this factor $(p<0.001)$. Sexual satisfaction is directly related to the quality of life and the quality of sexual relationships [34]. A study on HIV-infected people has reported that nearly $75 \%$ of participants in the research over the past 12 months were sexually active [13]. Other studies showed that many HIV-positive people had a reduced sexual desire as a result of fatigue, physical weakness, and depression associated with the disease [35]. Also, sexual desire may be reduced by the fear of contamination with other types of virus [36]. A study found that HIV-infected people need counselling about sex action and sexual satisfaction [37]. 
Another factor of reproductive health in HIV-positive women was coping with the disease. In this study, the support of the spouse, relatives, other patients, physicians and health care providers, spiritual health and relationship with God lead to acceptance of HIV. Cognitive-behavioural counselling increased the ability to cope with HIV $(p<0.000)$. The results of this study showed the effect of interventions on negative coping strategies, such as alcohol and drug usage, and the positive effect in coping strategies, such as the acceptance of the disease, reducing risky behaviours, and increasing the role of women in the sexual decision-making process [38].

Another factor of reproductive health of HIV-positive women was responsible behaviour. The results of the study showed that counselling with a cognitive-behavioural therapy approach did not affect this dimension $(p<0.13)$. In various studies, it has also been shown that one quarter to three quarters of HIV-positive women do not consistently use condoms in their sexual relationships [39]. The use of condoms, in addition to preventing unwanted pregnancy, prevents the transmission of the virus to the partner, which prevents the spread of disease and increases their reproductive rights [40].

In a study, counselling for people with HIV reduce was seen to the number of sexual partners and increase the consistency of condom use [41]. Also, many studies have shown the impact of counselling on increasing the use of condoms in people with HIV [42-44]. The results of these studies are not consistent with the present study. Also, a study showed that counselling interventions do not have an impact on the consistent use of dual contraceptive methods [33]. The results of this study were consistent with the present study. Because the health of people with HIV is very different from that of non-infected people, people with HIV face many challenges that are affected by the community and the stigma of the disease. Responsible behaviour of infected people is affected by communities and existing policies [45]. Therefore, training in this factor for both patients and health care providers as well as for the entire community is necessary. The results of the study showed that counselling with a cognitive-behavioural therapy approach had a positive effect on the total reproductive health score of HIV-positive women $(p<0.000)$.

The results of interventional studies have been shown to have a positive cognitive-behavioural therapy approach on reproductive and sexual health [46]. The results of the study showed that the total reproductive health score increased more one month after the intervention than immediately after the intervention, which was one of the research limitations, i.e. in the post-intervention follow-up, the researcher was not able to control the contribution of HIV-infected women in the training sessions by other researchers at the centre of high-risk behaviours of the Imam Hospital.

\section{Conclusions}

The results of this study show that counselling with a cognitive-behavioural therapy approach has a positive effect on reproductive health. Therefore, it is recommend- ed that, given the multidimensional aspect of reproductive health of infected women, counselling with a cognitive behavioural therapy approach in each dimension should be conducted with a greater number of sessions. Also, intervention programs are designed for stigma and discrimination reduction in women with HIV, because these factors effect the reproductive health of HIV-positive women.

\section{Conflict of interest}

The authors declare no potential conflicts of interest with respect to the research, authorship, and/or publication of this article.

\section{References}

1. World Health Organization, 2017. Consolidated guideline on sexual and reproductive health and rights of women living with HIV. Available from: http://www.who.int/reproductivehealth/publications/gender_rights/Ex-Summ-srhr-women-hiv/en/.

2. Centers for disease control and prevention, 2017. Unpublished AIDS report. Ministry of Health and Medical Education.

3. Teixeira LB, Pilecco FB, Vigo A, et al. Sexual and reproductive health of women living with HIV in Southern Brazil. Cadernos de Saúde Pública 2013; 29: 609-620.

4. Kendall T. Falling short of universal access to reproductive health: unintended pregnancy and contraceptive use among Mexican women with HIV. Cult Health Sex 2013; 15 Suppl 2: S166-S179.

5. Behboodi-Moghadam Z, Esmaelzadeh-Saeieh S, Ebadi A, et al. Development and Psychometric Evaluation of a Reproductive Health Assessment Scale for HIV-Positive Women. Shiraz E-Medical J 2016; 17: e38489.

6. Messersmith LJ, Semrau K, Anh TL, et al. Women living with HIV in Vietnam: desire for children, use of sexual and reproductive health services, and advice from providers. Reprod Health Matters 2012; 20 (39 Suppl): 27-38.

7. Wessman M, Aho I, Thorsteinsson K, et al. Perception of sexuality and fertility in women living with HIV: a questionnaire study from two Nordic countries. J Int AIDS Soc 2015; 18: 19962.

8. Siegfried N, Narasimhan M, Kennedy CE, et al. Using GRADE as a framework to guide research on the sexual and reproductive health and rights (SRHR) of women living with HIV - methodological opportunities and challenges. AIDS Care 2017; 29: 1088-1093.

9. Coleman SM, Rajabiun S, Cabral HJ, et al. Sexual risk behavior and behavior change among persons newly diagnosed with HIV: the impact of targeted outreach interventions among hard-to-reach populations. AIDS Patient Care STDS 2009; 23: 639-645.

10. Moradi G, Khoshravesh S, Hosseiny M. Situation of linkage between sexual and reproductive health and HIV-related policies in Islamic Republic of Iran - a rapid assessment in 2011-2. Int J Health Policy Manag 2015; 4: 131-136.

11. Loutfy M, Khosla R, Narasimhan M. Advancing the sexual and reproductive health and human rights of women living with HIV. J Int AIDS Soc 2015; 18 (6 Suppl 5): 20760.

12. Amin A. Addressing gender inequalities to improve the sexual and reproductive health and wellbeing of women living with HIV. J Int AIDS Soc 2015; 18 (6 Suppl 5): 20302.

13. Wekesa E. A new lease of life: sexual and reproductive behaviour among PLWHA in the ART era in Nairobi slums. London School of Economics and Political Science, London 2012.

14. Crepaz N, Passin WF, Herbst JH, et al.; HIV/AIDS Prevention Research Synthesis Team. Meta-analysis of cognitive-behavioral interventions on HIV-positive persons' mental health and immune functioning. Health Psychol 2008; 27: 4-14. 
15. Sudak DM. Cognitive behavioral therapy for depression. Psychiatr Clin North Am 2012; 35: 99-110.

16. Nguyen AL, Lake JE, Reid MC, et al. Attitudes towards exercise among substance using older adults living with HIV and chronic pain. AIDS Care 2017; 29: 1149-1152.

17. Brown LK, Kennard BD, Emslie GJ, et al. Effective treatment of depressive disorders in medical clinics for adolescents and young adults living with HIV: a controlled trial. J Acquir Immune Defic Syndr 2016; 71: 38-46.

18. Karamouzian M, Nasirian M, Sedaghat A, et al. HIV in Iran. Lancet 2014; 383: 1040.

19. Taylor SW, Psaros C, Pantalone DW, et al. "Life-Steps" for PrEP Adherence: Demonstration of a CBT-Based Intervention to Increase Adherence to Preexposure Prophylaxis (PrEP) Medication Among Sexual-Minority Men at High Risk for HIV Acquisition. Cogn Behav Pract 2017; 24: 38-49.

20. Hofmann SG, Asnaani A, Vonk IJ, et al. The efficacy of cognitive behavioral therapy: A review of meta-analyses. Cognit Ther Res 2012; 36: 427-440.

21. Orza L, Crone T, Mellin J, et al. Searching for the second R in sexual and reproductive health and... rights. J Adolescent Health 2017; 60: S10-S14.

22. Nedjat S, Moazen B, Rezaei F, et al. Sexual and reproductive health needs of HIV-positive people in Tehran, Iran: a mixed-method descriptive study. Int J Health Policy Manag 2015; 4: 591.

23. Behboodi-Moghadam Z, Nikbakht-Nasrabadi A, Ebadi A, et al. Fertility Desire in Iranian Women with HIV: A Qualitative Study. Iran J Public Health 2015; 44: 1126-1134.

24. Sanders LB. Women's voices: The lived experience of pregnancy and motherhood after diagnosis with HIV. J Assoc Nurses AIDS Care 2008; 19: 47-57.

25. Jones DL, Lopez M, Simons H, et al. Translation of a comprehensive health behavior intervention for women living with HIV: the SMART/EST Women's Program. Transl Behav Med 2013; 3 : 416-425.

26. Oramasionwu CU, Daniels KR, Labreche MJ, et al. The environmental and social influences of HIV/AIDS in sub-Saharan Africa: a focus on rural communities. Int J Environ Res Public Health 2011; 8: 2967-2979.

27. Tshuma N, Muloongo K, Setswe G, et al. Potential barriers to rapid testing for human immunodeficiency virus among a commuter population in Johannesburg, South Africa. HIV/AIDS (Auckland, NZ) 2015; 7: 11.

28. Barroso J, Relf MV, Williams MS, et al. A randomized controlled trial of the efficacy of a stigma reduction intervention for HIV-infected women in the Deep South. AIDS Patient Care STDS 2014; 28: 489-498.

29. Baipluthong B, Anekthananon T, Munsakul W, et al. Implementation and assessment of a prevention with positives intervention among people living with HIV at five hospitals in Thailand. PLoS One 2017; 12: e0170558.

30. Saadat M, Behboodi ZM, Saadat E. Comparison of depression, anxiety, stress, and related factors among women and men with human immunodeficiency virus infection. J Hum Reprod Sci 2015; 8: 48-51.

31 Senyonyi RM, Underwood LA, Suarez E, et al. Cognitive behavioral therapy group intervention for HIV transmission risk behavior in perinatally infected adolescents. Health 2012; 4: 1334.

32. Mupambireyi Z, Bernays S, Bwakura-Dangarembizi M, et al. "I don't feel shy because I will be among others who are just like me...": The role of support groups for children perinatally infected with HIV in Zimbabwe. Children and Youth Services Review 2014; 45: 106-113.

33. Parker L, Maman S, Pettifor A, et al. Feasibility analysis of an evidence-based positive prevention intervention for youth living with HIV/AIDS in Kinshasa, Democratic Republic of the Congo. AIDS Educ Prev 2013; 25: 135-150.
34. De Ryck I, Van Laeken D, Nöstlinger C, et al. Sexual satisfaction among men living with HIV in Europe. AIDS Behav 2012; 16: 225 230.

35. Siegel K, Schrimshaw EW, Lekas HM. Diminished sexual activity, interest, and feelings of attractiveness among HIV-infected women in two eras of the AIDS epidemic. Arch Sex Behav 2006; 35: 437-449.

36. Courtenay-Quirk C, Pals SL, Colfax G, et al. Factors associated with sexual risk behavior among persons living with HIV: gender and sexual identity group differences. AIDS Behav 2008; 12: 685 .

37. Keegan A, Lambert S, Petrak J. Sex and relationships for HIV-positive women since HAART: a qualitative study. AIDS Patient Care STDS 2005; 19: 645-654.

38. Jones DL, Ross D, Weiss SM, et al. Influence of partner participation on sexual risk behavior reduction among HIV-positive Zambian women. J Urban Health 2005; 82: iv92-iv100.

39. Walusaga HA, Kyohangirwe R, Wagner GJ. Gender differences in determinants of condom use among HIV clients in Uganda. AIDS Patient Care STDS 2012; 26: 694-699.

40. Saeieh SE, Nasrabadi AN, Ebadi A, et al. Contraception use among Iranian women with HIV: a qualitative study. Glob J Health Sci 2016; 8: 199.

41. Lightfoot MA, Kasirye R, Comulada WS, et al. Efficacy of a culturally adapted intervention for youth living with HIV in Uganda. Prevention Science 2007; 8: 271-273.

42. Futterman D, Shea J, Besser M, et al. Mamekhaya: a pilot study combining a cognitive-behavioral intervention and mentor mothers with PMTCT services in South Africa. AIDS Care 2010; 22 : 1093-1100.

43. Klein CH, Lomonaco CG, Pavlescak R, et al. WiLLOW: Reaching HIV-positive African-American women through a computer-delivered intervention. AIDS Behav 2013; 17: 3013-3023.

44. Sarnquist CC, Moyo P, Stranix-Chibanda L, et al. Integrating family planning and prevention of mother to child HIV transmission in Zimbabwe. Contraception 2014; 89: 209-214.

45. Matthews LT, Crankshaw T, Giddy J, et al. Reproductive decision-making and periconception practices among HIV-positive men and women attending HIV services in Durban, South Africa. AIDS Behav 2013; 17: 461-470.

46. Robinson JL, Narasimhan M, Amin A, et al. Interventions to address unequal gender and power relations and improve self-efficacy and empowerment for sexual and reproductive health decision-making for women living with HIV: A systematic review. PLoS One 2017; 12: e0180699. 